\title{
CARACTERÍSTICAS DE SEGURANÇA E NÍVEIS DE RUÍDO EM TRATORES AGRÍCOLAS
}

\author{
Paula Cristina Natalino Rinaldi ${ }^{1}$, Haroldo Carlos Fernandes ${ }^{2}$, João Cleber Modernel da \\ Silveira ${ }^{3}$, Ronaldo Goulart Magno Júnior ${ }^{4}$, Luciano José Minetti ${ }^{5}$
}

\section{RESUMO}

Este trabalho foi conduzido na Universidade Federal de Viçosa - MG com o objetivo de verificar os requisitos de segurança e medir os níveis de ruído emitido pelos tratores agrícolas em uso pela instituição. Foram avaliados 29 tratores, sendo inspecionados requisitos de segurança relativos ao posto de operação, acesso, comandos, proteção de partes móveis, disponibilização de avisos contra riscos de acidentes e requisitos necessários para tráfego em rodovias. Os níveis de ruído foram medidos em quatro pontos próximos ao operador. Também foi aplicado um questionário aos operadores com relação ao tempo de serviço, uso de protetor auricular, dores na coluna e perda de audição. Verificaram-se altos níveis de ruído e falta de alguns requisitos de segurança, que são justificados devido ao tempo de uso dos tratores agrícolas.

Palavras-chave: segurança operacional, ergonomia e máquinas agrícolas.

\section{ABSTRACT \\ Safety characteristics and noise level in agricultural tractors}

This study was carried out to determine the safety requirements and to measure the noise levels emitted by agricultural tractors used at the Universidade Federal de Viçosa, MG. Evaluation was carried out in twenty nine tractors, by inspecting the following factors: safety requisites in the operational cabin such as access, commands, protection from movable part, warning availability against accident risks and necessary requirements for traffic on highways. The noise levels were measured at four points next the operator. The operators were asked to respond to questions regarding service duration, protecting headphone use, audition loss, and back pains. High noise levels and lack of some safety requisites were identified, due to long use time of the agricultural tractors.

Keywords: operational safety, ergonomics and agricultural machines.

\footnotetext{
Recebido para publicação em 11.04.2007

${ }^{1}$ Eng'a.Agrícola, MS em Eng. Agríc. - Mecanização Agríc., UFV, Viçosa-MG. Fone: (0xx31) 3899-1860. email: pcnrinaldi @yahoo.com.br

${ }^{2}$ Eng $^{\circ}$ Agrícola, Professor Associado do Dpo de Eng. Agrícola da UFV - MG. Fone: (0xx31) 3899- 1883. email: haroldo@ufv.br

${ }^{3}$ Eng $^{\circ}$ Agrícola, DS em Eng. Agrícola - Mecanização Agrícola, UFV, Viçosa-MG. Fone: (0xx31) 3899-1860, e-mail: jcmodernel@ vicosa.ufv.br

${ }^{4}$ Eng ${ }^{\circ}$ Agrônomo, Mestrando em Engenharia Agrícola - Mecanização Agrícola, UFV, Viçosa - MG. Fone: (0xx31) 38992046. email: ronaldoufv@yahoo.com.br

${ }^{5}$ Eng $^{\circ}$ Florestal, Professor Adjunto do Departamento de Engenharia Elétrica e de Produção da Universidade Federal de Viçosa - MG. Fone: (0xx31) 3899- 2721. email: minette@ufv.br
} 


\section{INTRODUÇÃO}

A atividade de operação de tratores agrícolas engloba dois fatores importantes, o operador e a máquina, constituindo assim a relação homem-máquina. A ergonomia e a segurança no posto de operação agem sobre essa relação buscando a eficiência da realização do trabalho com o menor risco possível ao trabalhador.

Quando o sistema homem-máquina é ineficaz o operador pode ser exposto a elevada carga de trabalho, física e/ou mental, ocasionando perda na produtividade e na qualidade do trabalho, aumentando a ocorrência de acidentes e o desenvolvimento de doenças ocupacionais.

A intensificação do uso de máquinas agrícolas no Brasil começou a partir da década de 60 , fruto do processo de modernização da agricultura. $O$ trator destaca-se entre estas máquinas, sendo considerado por alguns autores como a base da moderna mecanização agrícola (Schlosser et al., 2002).

Os levantamentos estatísticos nacionais e internacionais sobre acidentes agrícolas mostram expressivo número de acidentes envolvendo tratores agrícolas. Nos registros do Instituto Nacional de Segurança Social, o índice de acidentes com máquinas agrícolas é relativamente baixo $(14,1 \%)$ se comparado aos acidentes com ferramentas manuais $(34,2 \%)$ da atividade canavieira. No entanto, outras citações evidenciam a participação do trator nos acidentes ocorridos no meio rural (Corrêa et al., 2005)

O nível de ruído a que o operador está exposto tem relação direta com o aumento da possibilidade de acidentes, pois o ruído excessivo pode causar irritação e perda da concentração.

A exposição ao ruído é uma das principais causas das perdas auditivas relacionadas ao trabalho. O ruído é um agente físico emitido em boa parte dos processos industriais, máquinas, ferramentas e motores. Essa exposição pode ser constante ou intermitente. O tempo de exposição, a intensidade do ruído e a susceptibilidade do indivíduo têm relação direta com os danos à saúde. Seus efeitos nocivos não se restringem à audição, podendo acarretar distúrbios emocionais, cardiovasculares, fadiga e estresse.

Santos Filho (2002) ao avaliar os níveis de ruído causados por um trator sem cabine, em diferentes velocidades de trabalho, concluiu que os valores indicaram uma condição de trabalho extremamente desconfortável para o tratorista, proporcionando grande risco de perda da audição. O trator, mesmo encontrando-se parado com o motor ligado, pode apresentar altos níveis de ruído. Kahil \& Gamero (1997) avaliaram os níveis de ruído emitidos por cinco tratores na condição estática e concluíram que os mesmos emitiram níveis de ruído acima do permitido pela legislação, que seria no máximo $85 \mathrm{~dB}$ para uma exposição diária de oito horas.

Schlosser \& Debiasi (2002) estudando o conforto e a preocupação com o operador, concluíram que nos tratores não cabinados, os níveis de ruído ficaram acima do limite considerado salubre, mas com a introdução da cabine esse nível reduziu em aproximadamente $5 \mathrm{~dB}$.

Muitos são os fatores que contribuem para a ocorrência de acidentes no meio rural. Nesse sentido, um dos fatores que merece destaque é a falta de exigência por parte dos usuários na inserção de requisitos de segurança nas máquinas agrícolas utilizadas no Brasil, pois nem sempre quem as adquire é quem as opera. De acordo com Mialhe (1996), os critérios de ergonomia e segurança foram incorporados recentemente na formulação de metodologias de ensaio de máquinas agrícolas e ainda há falta de informação aos projetistas sobre a legislação, normas regulamentadoras e normas técnicas.

Grande parte dos acidentes envolvendo tratores poderia ser evitada se as máquinas envolvidas fossem dotadas de dispositivos de segurança, se os equipamentos de proteção fossem utilizados e se as regras de segurança fossem observadas durante a jornada de trabalho na realização das atividades.

Freeman (1999) descreve a importância da estrutura de proteção contra capotamento (EPCC) nos tratores agrícolas. Essa estrutura pode eliminar ou minimizar um acidente de trabalho, pois se constituem em uma proteção relevante aos operadores em caso de tombamentos. 
Segundo Butierres (1996) uma solução para alertar os operadores para tais perigos seria a utilização de símbolos, palavras de alerta, sinais sonoros e sinais luminosos com cores características nos tratores agrícolas.

Como este trabalho objetivou-se avaliar as condições de segurança dos tratores agrícolas, a medição dos níveis de ruído emitidos pelos mesmos e a aplicação de um questionário aos operadores dos tratores agrícolas da instituição em que foi realizado o estudo.

\section{MATERIAL E MÉTODOS}

O presente trabalho foi conduzido no campus da Universidade Federal de Viçosa (UFV), Viçosa, MG, no período de fevereiro a março de 2007. As máquinas, equipamentos e ferramentas utilizadas na avaliação foram:

- 29 tratores de diversas marcas, modelos e anos de fabricação, em uso pela instituição;

- Decibelímetro digital da marca MINIPA, modelo MSL-1350;

- Régua graduada.

Alguns itens de segurança quando presentes nas máquinas agrícolas podem além de garantirem o conforto e o bem-estar do operador, impedir acidentes de trabalho. Os itens verificados nos tratores foram observados em conformidade com as normas ISO 4253 (1993) e ABNT NBR ISO 4254-1 (1999). Outros requisitos não especificados nas normas mencionadas anteriormente, mas importantes para a segurança e necessários para o tráfego em rodovias avaliados de acordo com o Código Brasileiro de Trânsito (Lei 9503, de 23/09/1997).

A ergonomia e a segurança de um determinado trator agrícola envolvem a avaliação da presença e o estado de conservação dos itens de segurança. Sendo assim, a coleta dos dados seguiu os critérios descritos abaixo.

Foram utilizadas duas classificações para a identificação do posto de operação. A denominação "acavalado" foi atribuída quando o monobloco do trator ficava entre as pernas do operador, ficando os pés apoiados em estribos colocados lateralmente a esse monobloco. A classificação "plataforma" foi atribuída aos tratores quando o posto de operação era plano e montado sobre o monobloco. A superfície do piso do posto de operação foi considerada como antiderrapante quando apresentava orifícios ou possuía material emborrachado.

A facilidade de acesso do operador ao seu posto de operação pode ser feita com 0 auxílio de degraus e apoio nos tratores. A norma ABNT NBR ISO 4254-1 (1999) estabelece que os acessos com mono ou multidegraus devam ter largura igual ou superior a $200 \mathrm{~mm}$, e altura do primeiro degrau de no máximo $550 \mathrm{~mm}$. A superfície dos degraus foi considerada como antiderrapante quando era constatada a presença de rugosidades.

Os comandos, regulagem do volante de direção, acionamento e desligamento da TDP, regulagens do assento e apoio para os braços do operador, foram verificados por meio da inspeção nos tratores e com o auxílio das informações dos respectivos operadores, seguindo a norma ABNT NBR ISO 4254-1 (1999).

Alguns itens, mesmo não sendo necessários para a segurança do operador, quando presentes podem proporcionar o conforto e conseqüentemente 0 maior rendimento na execução do trabalho. A presença de toldo solar, isolamento térmico do motor e o direcionamento dos gases de escape são fatores que contribuem para garantir esse conforto. De acordo com ABNT NBR ISO 4254-1 (1999), os gases de escape devem estar acima da cabine e no caso dos tratores não cabinados estes devem estar posicionados em posição superior ao toldo solar. 
A estrutura de proteção contra capotamento quando presente nos tratores agrícolas pode garantir que o trabalhador não seja vítima de um acidente fatal, principalmente no caso de um tombamento lateral ou capotamento das máquinas agrícolas. A presença dessas estruturas foi verificada nos tratores, sendo a classificação de acordo com a fixação no chassi (dois ou quatro pontos).

A presença de estruturas que impeçam o contato direto do operador com partes móveis do trator, como polia do motor, pás do ventilador e eixo da tomada de potência, diminuem o risco de acidentes. Para especificação dos tipos de proteção da tomada de potência (TDP), foram considerados os definidos na ABNT NBR ISO 4254-1 (1999). A denominação caixa ou invólucro foi atribuída quando todos os lados próximos à TDP se encontravam protegidos, e escudo ou tampa, quando pelo menos um lado era protegido. Pode existir também a presença de um invólucro adicional, normalmente constituído de uma capa rosqueável, sendo recomendável o seu uso quando a TDP não estiver acionada.

Foi verificada a presença de avisos em forma de texto, figuras ou símbolos que informem sobre o risco de tombamento, risco de giro da tomada de potência (TDP), partida do motor e orientação quanto ao acoplamento de implementos agrícolas.

Os tratores agrícolas para que possam transitar em rodovias com o mínimo de segurança devem ser equipados com farol dianteiro, luzes de freio, de advertência, de direção e de ré, buzina, cinto de segurança e espelho retrovisor em pelo menos um dos lados.

O nível de ruído, emitido pelos tratores, foi determinado de acordo com a NBR 9999 (ABNT, 1987), sendo esta uma norma específica para medir ruídos em tratores e seus efeitos nos operadores.

Para medição dos níveis de ruído, foi utilizado um decibelímetro digital, marca MINIPA e modelo MSL-1350. A escala utilizada para medir o nível de ruído dos tratores foi o decibel $d B(A)$. Embora tenha sido observada uma condição climática favorável, utilizou-se o protetor de ventos no microfone do decibelímetro em todas as amostragens, a fim de uniformizar as condições de leitura e evitar a influência de prováveis rajadas de vento.

A instituição possui 29 tratores em uso, mas apenas 26 estavam em perfeitas condições de funcionamento na época da coleta de dados, e como não se tinha previsão de conserto, procedeu-se a medição ruído com aqueles que encontravam em funcionamento. Durante a medição dos níveis de ruído, o operador manteve-se na sua posição de trabalho e os tratores em marcha neutra e motor com rotação de $1700 \mathrm{rpm}$ sem carga. De acordo com a norma NBR 9999 (ABNT, 1987), o microfone do medidor foi posicionado a uma altura de $20 \mathrm{~cm}$ de distância em relação ao ouvido que apresentava um maior nível de ruído. Para efeito de comparação, os níveis de ruído também foram coletados na lateral esquerda, lateral direita, parte frontal e traseira, a $20 \mathrm{~cm}$ em relação ao operador.

Os 20 operadores em atividade na instituição foram questionados quanto ao uso de protetor auricular, se apresentavam queixas de dores na coluna e percebiam alguma perda da audição. Foi levantado também o tempo de serviço de cada operador nesta função e anotados todos os comentários para uma melhor discussão dos resultados.

A análise dos dados foi feita por meio da estatística descritiva, relacionando-se os percentis de presença/inoperantes para cada item.

\section{RESULTADOS E DISCUSSÕES}

Os 29 tratores em uso nas áreas visitadas apresentavam a seguinte distribuição por idade: menos de 10 anos: $31,0 \%$; de 11 a 20 anos: $13,8 \%$ e acima de 20 anos: $55,2 \%$. Os dados mostraram que a maior parte da frota dos tratores da instituição encontrava-se com mais de 20 anos de uso.

No Quadro 1 encontra-se a classificação do percentual em relação às marcas dos tratores em uso. 
Quadro 1. Percentual dos tratores de acordo com a marca

\begin{tabular}{cc}
\hline Marca & \% de presença \\
\hline AGRALE & 6,90 \\
DEUTZ & 3,45 \\
FORD & 10,34 \\
JOHN DEERE & 6,90 \\
MASSEY FERGUSON & 34,48 \\
NEW HOLLAND & 6,90 \\
VALMET & 20,69 \\
VALTRA & 10,34 \\
\hline
\end{tabular}

A média da altura do primeiro degrau nos tratores foi de $494,75 \mathrm{~mm}$ (desvio padrão: $46,65 \mathrm{~mm}$ ), enquanto que a largura média dos degraus foi de $329 \mathrm{~mm}$ (desvio padrão: $90,74 \mathrm{~mm}$ ). A altura e largura dos degraus enquadraram-se nos padrões da ABNT NBR 4254-1 (1999).

No Quadro 2 pode ser observado 0 percentual de presença das características do posto de operação e seu acesso aos tratores em estudo. Com relação ao tipo do posto de operação, o "acavalado" foi o que apresentou uma percentagem de presença de $65,5 \%$, sendo que este tipo causa um maior desconforto ao operador em relação ao tipo "plataforma".

A maioria, $88,7 \%$, dos postos de operação dos tratores apresentou superfície antiderrapante, 0 que garante maior segurança em relação à escorregamento. A superfície antiderrapante dos degraus foi mediamente baixa, $65,0 \%$, devendo ser motivo de atenção no momento da sua utilização. O número de ocorrências do apoio, para facilitar o acesso ao posto de operação foi baixo, $40,0 \%$, sendo assim, os operadores utilizam, na maioria das vezes, o volante para se erguerem e se posicionarem nos assentos.

A facilidade em acessar os comandos do posto de operação diminui o esforço físico do operador e aumenta a possibilidade do acionamento rápido de determinado dispositivo em uma emergência. No Quadro 3 são apresentadas as características dos comandos do posto de operação e do assento. Como pode ser observado na referida tabela, poucos tratores, $10,34 \%$, apresentaram regulagem do volante de direção.

Quadro 2. Características do posto de operação e seu acesso

\begin{tabular}{|c|c|}
\hline Item avaliado & \% presença \\
\hline TIPO DO POSTO DE OPERAÇÃO & -------- \\
\hline - Plataforma & 34,5 \\
\hline - Acavalado & 65,5 \\
\hline - Superfície antiderrapante & 88,7 \\
\hline ACESSO AO POSTO DE OPERAÇÃO & ------- \\
\hline Existência de degrau & 65,5 \\
\hline Altura do $1^{\circ}$ degrau $=550 \mathrm{~mm}^{(1)}$ & 100,0 \\
\hline Largura do $1^{\circ}$ degrau $=200 \mathrm{~mm}^{(1)}$ & 90,0 \\
\hline Superfície antiderrapante ${ }^{(1)}$ & 65,0 \\
\hline Apoio para acesso ao posto de operação ${ }^{(1)}$ & 40,0 \\
\hline
\end{tabular}

(1) em relação ao total de tratores com degraus 
A norma ABNT NBR 4254-1 (1999) estabelece que todas as fontes de potência devam ser montadas com um dispositivo que permita rápido desligamento. Apenas 27,59\% dos tratores apresentaram nos seus respectivos painéis de controle luz indicativa do acionamento da tomada de potência (TDP), mas 6,90\% desse total não estavam funcionando. A não necessidade de esforço auxiliar e acessibilidade da TDP apresentaram valores superiores a $60 \%, 65,52 \%$ e $62,07 \%$, respectivamente.

A existência no painel de um indicativo do bloqueio do diferencial é importante para alertar do acionamento inadvertido. Esse é um requisito normativo pouco presente, $17,24 \%$, nos tratores em uso e 3,45\% do valor anteriormente mencionado não apresentava esse dispositivo em perfeitas condições de funcionamento.

De acordo com a norma ISO 4253 (1993), as regulagens horizontal e vertical são obrigatórias. Pelos resultados apresentados no Quadro 3 observa-se regulagem horizontal bastante satisfatória, 96,55\%, mas a regulagem vertical e do encosto insatisfatórias, com $6,90 \%$ e $3,45 \%$, respectivamente.

Segundo CORRÊA et al. (2005), com exceção dos ajustes longitudinal e vertical do assento, os demais itens verificados neste levantamento não são exigidos em documentos normativos, mas contribuem para a redução da fadiga do operador.

O apoio para os braços no assento do operador também é um dos itens que garantem maior conforto ao operador. No levantamento, os tratores apresentaram $31,03 \%$ de presença em relação a esse item e $6,90 \%$ em relação a estes $31,03 \%$, encontravam-se com 0 apoio do braço esquerdo, direito ou ambos quebrados.

No Quadro 4 apresentou-se outras características do posto de operação, podendo-se observar que $82,76 \%$ possuía estrutura de proteção contra sol e intempéries. Essa estrutura não garante a proteção do operador no caso de acidentes, para a completa segurança seria necessária a presença da estrutura de proteção contra capotamento (EPCC), que no presente estudo representou $40,83 \%$ nos tratores. Nenhum dos tratores possuía cabine de segurança e certificação da estrutura de proteção quando a máquina agrícola possuía EPCC.

A presença de cabine além de proporcionar maior proteção no caso de acidentes, diminuiu a exposição à poeira, ao calor e ruído; e a certificação da estrutura de proteção é uma declaração do fabricante da máquina atestando 0 atendimento da estrutura às normas técnicas. Diante disto justifica-se a verificação desses requisitos de segurança.

Quadro 3. Características dos comandos do posto de operação e do assento

\begin{tabular}{lc}
\hline \multicolumn{1}{c}{ Item avaliado } & \% de presença \\
\hline Regulagem do volante de direção & 10,34 \\
\hline ACIONAMENTO/DESLIGAMENTO DA TDP ${ }^{(1)}$ & ------ \\
\hline - Luz no painel & 27,59 \\
- Sem necessidade de esforço auxiliar & 65,52 \\
- Acessibilidade & 62,07 \\
Indicador do bloqueio do diferencial & 17,24 \\
\hline ASSENTO DO OPERADOR & ------- \\
\hline - Regulagem horizontal & 96,55 \\
- Regulagem vertical & 6,90 \\
- Regulagem do encosto & 3,45 \\
- Apoio para os braços & 31,03 \\
\hline
\end{tabular}

(1) TDP: Tomada de potência 
Quadro 4. Outras características do posto de operação

\begin{tabular}{lc}
\multicolumn{1}{c}{ Item avaliado } & \% de presença \\
\hline Proteção contra sol/intempéries & 82,76 \\
Proteção contra calor do motor & 13,79 \\
Direcionamento do escape acima do toldo & 44,83 \\
solar & ------- \\
\hline TIPO DE ESTRUTURA DE PROTEÇÃO & 0,00 \\
\hline - Cabine de segurança & 6,90 \\
- EPCC de 4 pontos & 37,93 \\
- EPCC de 2 pontos & 55,17 \\
\hline - Ausente & 0,00 \\
\hline Certificação da estrutura de proteção ${ }^{(1)}$ &
\end{tabular}

(1) Em relação aos tratores que apresentavam estrutura de proteção

Quadro 5. Características da proteção de partes móveis

\begin{tabular}{lc}
\multicolumn{1}{c}{ Item avaliado } & \% de presença \\
\hline PROTEÇÃO DE PARTES MÓVEIS & $---\cdot--$ \\
\hline - Polia do motor & 86,21 \\
- Pás do ventilador & 86,21 \\
- Tomada de potência & 79,31 \\
\hline TIPO DE PREOTEÇÃO DA TDP ${ }^{(1)}$ & $---\cdot--$ \\
\hline - Escudo ou tampa & 13,79 \\
- Invólucro & 24,14 \\
\hline Invólucro adicional & 55,17 \\
\hline (1) TDP: tomada de potência &
\end{tabular}

O direcionamento dos gases de escape acima do toldo solar representou $44,83 \%$ de presença nos tratores. Essa percentagem relativamente baixa também foi observada por CORRÊA et al. (2005) que encontrou $62,6 \%$ de presença nos 487 tratores em uso em 270 propriedades no Estado de São Paulo.

Segundo a norma ABNT NBR 4254-1 (1999), em geral todas as partes móveis devem ser consideradas perigosas, neste trabalho deu-se ênfase a algumas características de proteção de partes móveis (Quadro 5).

Os itens de proteção relacionados à polia do motor, pás do ventilador e tomada de potência apresentaram elevado índice de ocorrência, $86,21 \%, 86,21 \%$ e $79,31 \%$, respectivamente.
Os três tipos de proteções projetadas para evitar o contato de uma pessoa ou da roupa com partes móveis podem ser classificados de acordo com a norma ABNT NBR 4254-1 (1999). Observa-se na Tabela 5 que a proteção escudo ou tampa apresentou $13,79 \%$ de presença, já o tipo invólucro, $24,14 \%$.

Dos tratores analisados, $55,17 \%$ vieram de fábrica com a proteção tipo invólucro adicional e apenas $3,45 \%$ desse total haviam perdido esta proteção, já que não existe um local para o mesmo ser fixado quando a tomada de potência não estiver sendo utilizada. Como já foi mencionado a maioria dos tratores da instituição apresentam mais de 20 anos de uso, evidenciando que o valor de $3,45 \%$ dos tratores que por algum motivo perderam o invólucro poderia ser considerado como insignificante. 
Quadro 6. Presença de avisos de advertência

\begin{tabular}{lc}
\hline \multicolumn{1}{c}{ Item avaliado } & \% de presença \\
\hline Risco de tombamento & 6,90 \\
Risco de giro da TDP ${ }^{(1)}$ & 10,34 \\
Partida do motor & 10,34 \\
Orientação sobre acoplamento & 6,90 \\
\hline
\end{tabular}

${ }^{(1)}$ TDP: tomada de potência

De acordo com a norma ABNT NBR 4254-1 (1999), os avisos de advertência duráveis devem ser fixados nas partes da máquina que oferecem perigo para 0 operador. Também estão incluídas situações onde o abaixamento inadvertido de partes do equipamento possa causar perigo. Advertências específicas de segurança ou de perigo devem ser indicadas no aviso.

Os resultados da percentagem de presença dos avisos de advertência podem ser verificados na Tabela 6 .

Os baixos níveis de presença de avisos em todos os itens avaliados nos tratores indicam que este aspecto de prevenção não recebeu merecida atenção por parte dos projetistas e fabricantes.

Os itens, risco de tombamento e orientação sobre acoplamento apresentaram $6,90 \%$ de presença, enquanto os demais somaram $20,68 \%$.

Alguns itens são necessários para garantir a segurança durante o trânsito das máquinas agrícolas em rodovias.
Embora projetado para operar em zonas rurais, às vezes torna-se necessário esse deslocamento em rodovias para atender outras áreas que serão utilizadas.

A incorporação de itens de segurança como faróis, luz de direção, luz de advertência, luz de freio, buzina, espelho retrovisor e cinto de segurança, são, portanto, uma necessidade.

No Quadro 7 pode-se observar que com exceção do farol dianteiro, 96,55\%, os demais dispositivos apresentaram baixo índice de presença. Com relação ao item luz de ré, nenhum dos tratores em estudo apresentava esse dispositivo em seus componentes.

Alguns dispositivos mesmo existindo nos tratores em estudo, encontravam-se inoperantes por falta de manutenção corretiva e tempo de uso. Os percentuais dos itens inoperantes para o trafegabilidade em rodovias encontramse na Tabela 7 . Observa-se na mesma que o item que apresentou o maior percentual, $13,79 \%$, foi para a buzina.

Quadro 7. Características dos requisitos para tráfego em rodovias

\begin{tabular}{lcc}
\hline \multicolumn{1}{c}{ Item avaliado } & \% de presença & \% de inoperante \\
\hline Farol dianteiro & 96,55 & 6,90 \\
Luz de direção & 20,69 & 3,45 \\
Luz de advertência & 20,69 & 0,00 \\
Luz de freio & 44,83 & 3,45 \\
Luz de ré & 0,00 & 0,00 \\
Buzina & 27,59 & 13,79 \\
Espelho retrovisor & 6,90 & 0,00 \\
Cinto de segurança & 24,14 & 6,90 \\
\hline
\end{tabular}


Na Figura 1, mostra-se os níveis de ruído medidos em todas as posições em relação aos operadores nos tratores em estudo.

Apenas um dos tratores se enquadrou dentro das normas NR 15, exposição máxima de $85 \mathrm{~dB}(\mathrm{~A})$ para uma máxima exposição diária permissível de 8 horas de trabalho. Esse trator com seis anos de uso apresentou um nível de ruído no ouvido esquerdo de $80 \mathrm{~dB}(\mathrm{~A})(\mathrm{a})$, isso se deve ao estado de conservação da máquina e pelo fato da mesma não realizar trabalhos pesados, e o mesmo também apresentou um menor nível na medição da parte traseira, 88,4 dB $(A)$.

$\mathrm{Na}$ posição lateral esquerda o maior ruído medido foi 95,4 dB (A) com 33 anos de uso, provavelmente esse elevado nível se deva ao tempo de uso, pois outros tratores com tempo de uso similar, apresentaram níveis de ruído bem próximos do mencionado anteriormente.

$\mathrm{Na}$ lateral direita, o menor e o maior nível de ruído foi de 88 e $95,8 \mathrm{~dB}(\mathrm{~A})$, respectivamente. $O$ baixo valor foi devido ao bom estado de conservação e pouco tempo de uso (6 anos), além do escapamento estar bem acima do toldo solar. Entretanto, o alto valor foi devido ao trator apresentar 27 anos de uso e suas más condições de conservação, o que pode ser comprovado devido ao fato de além de alto índice na lateral direita, também apresentar os maiores índices na parte frontal e traseira, 97 e $94,9 \mathrm{~dB}(\mathrm{~A})$, respectivamente.

O menor nível de ruído na parte frontal foi $85,7 \mathrm{~dB}(\mathrm{~A})$, sendo este valor bem próximo ao exigido pela NR 15. Esse trator trabalha em operações diversas e encontra-se em excelente estado de conservação.

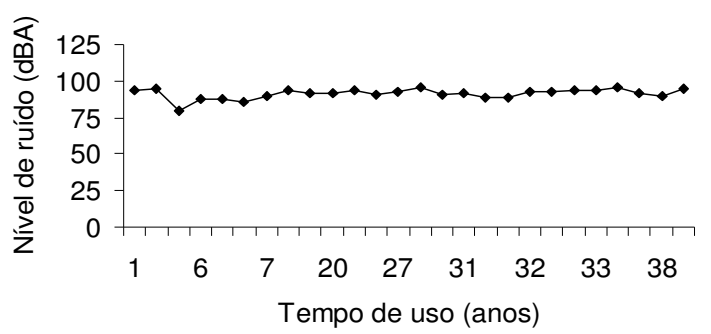

(a)

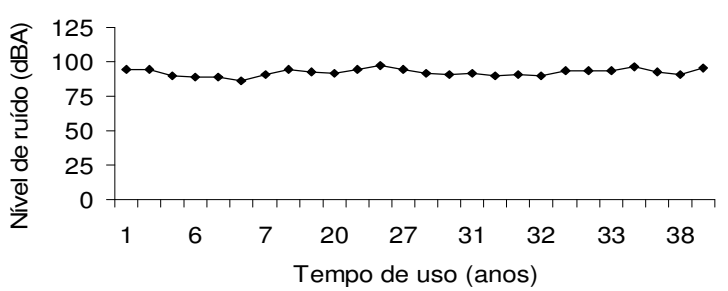

(c)

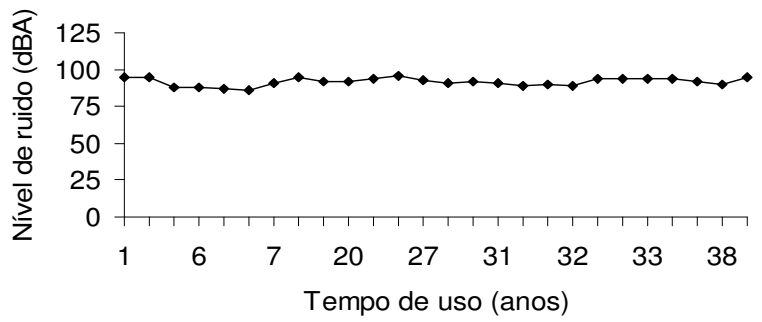

(b)

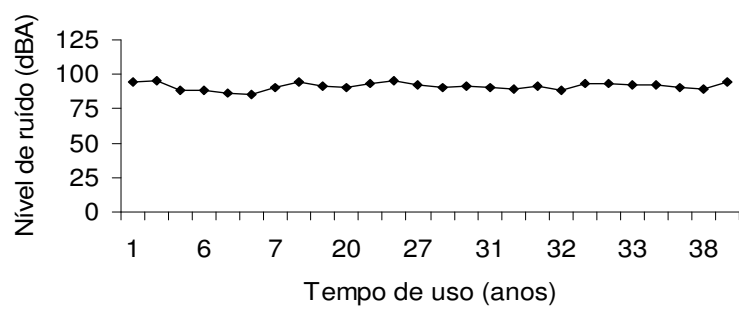

(d)

Figura 1. Níveis de ruído medidos nos tratores em todas as posições em relação ao operador, lateral esquerda (a), lateral direita (b), frontal (c) e traseira (d), em função do tempo de uso 
Dos operadores questionados, $50 \%$, se queixaram de dor na coluna, e $15 \%$ apresentam dificuldade de audição. O tempo médio de trabalho dos operadores é de 16 anos.

Apenas $33 \%$ dos trabalhadores utilizavam protetor auricular, e quando questionados da sua não utilização, alguns diziam incomodar, atrapalhar o serviço e até cogitavam da possibilidade de envolvimento em acidente pelo fato deste impossibilitar a perfeita audição do ruído de uma eventual máquina que se aproxima e que não esteja sendo avistada.

\section{CONCLUSÃO}

- A maior parte dos tratores avaliados apresentou menos de $40 \%$ de itens de requisitos de segurança.

- Os níveis de ruído emitidos ficaram acima do máximo permitido pelas normas regulamentadoras.

- Apesar do elevado tempo de uso (idade), os tratores analisados, em geral apresentam um bom estado de conservação e funcionamento.

- A operação de tratores agrícolas é uma atividade desgastante que pode causar doenças ocupacionais.

\section{REFERÊNCIAS BIBLIOGRÁFICAS}

ASSOCIAÇÃO BRASILEIRA DE NORMAS TÉCNICAS. NBR ISO 4254-1 - Tratores e máquinas agrícolas e florestais - Recursos técnicos para garantir a segurança - Parte 1: Geral. Rio de Janeiro: ABNT, 1999. 13 p.

ASSOCIAĈ̃O BRASILEIRA DE NORMAS TÉCNICAS. NBR 9999. Medição do nível de ruído no posto de operação de tratores agrícolas. Rio de Janeiro: ABNT, 1987. 21p.

BUTIERRES, E. Normalização de adesivos de segurança para uso em máquinas agrícolas. In: WORSHOP SOBRE MECANIZAÇÃO AGRÍCOLA NA REGIÃO DE CLIMA TEMPERADO, 2., 1996, Pelotas. Anais... Pelotas: UFPEL/FAEM, EMBRAPA/CPACT, UFSM/CT, 1996. p.131-133.
CÓDIGO BRASILEIRO DE TRÂNSITO. Lei 9503. Disponível em: <http://www.planalto.gov.br/CCIVIL/LEIS/L9 503.htm>. Acesso em 09 de março de 2007.

CORRÊA, I.M; YAMASHITA, R.Y; FRANCO, A.V.F; RAMOS, H.H. Verificação de requisitos de segurança de tratores agrícolas em alguns municípios do estado de São Paulo. Revista Brasileira de Saúde Ocupacional, v.30, n.111, p. 25-34, 2005.

INTERNATIONAL STANDARTIZATION FOR ORGANIZATION. ISO 4253 - Agricultural tractors - Operator's seating accommodation Dimensions. Genève: ISO, 1993. 4p.

KAHIL, M.A.; GAMERO, C.A. Níveis de ruído: Avaliação ergonômica de alguns tratores e equipamentos agrícolas. Energia na Agricultura, Botucatu, v.12, n.3, p.46-53, 1997.

FREEMAN, S.A. Potential impact of a ROPS retrofit policy in central lowa. St. Joseph: ASAE, 1999. 10p. (ASAE. Paper, 99-109).

MIALHE, L.G. Máquinas agrícolas: ensaios \& certificação. Piracicaba, São Paulo, FEALQ. 1996. 722 p.

NORMA REGULAMENTADORA. NR 15 Atividades e operações insalubres. Segurança e Medicina do Trabalho. Lei 6.514 de 22 de dezembro de 1977. São Paulo, 2002.

SANTOS FILHO, P.F. Avaliação dos níveis de ruído e vibração vertical no assento de um trator agrícola de pneus utilizando um sistema de aquisição automática de dados. 2002. 53p. Dissertação (Mestrado em Engenharia Agrícola) Curso de Pós-graduação em Mecanização Agrícola, Universidade Federal de Viçosa, Viçosa.

SCHLOSSER, J.F.; DEBIASI, H. Conforto, preocupação com o operador. Revista Cultivar Máquinas. n. 1, p. 3-9, 2002. (Caderno Técnico).

SCHLOSSER, J.F; DEBIASI, $\mathrm{H}$; PARCIANELLO, G; RAMBO. L. Antropometria aplicada aos operadores de tratores agrícolas. Revista Ciência Rural, v.32, n.6, 2002. 